\title{
Advanced Plasma Pyrolysis Assembly (PPA) Reactor and Process Development
}

\author{
Richard R. Wheeler, Jr. ${ }^{1}$, Neal M. Hadley ${ }^{2}$, and Roger W. Dahl ${ }^{3}$ \\ UMPQUA Research Company, Myrtle Creek, OR 97457 \\ Morgan B. Abney ${ }^{4}$ and Zachary Greenwood ${ }^{5}$ \\ NASA Marshall Space Flight Center, Huntsville, AL 35812 \\ Lee Miller ${ }^{6}$ \\ ECLS Technologies, Huntsville, AL 35802 \\ and \\ Amber Medlen ${ }^{7}$ \\ Lauderdale County High School, Rogersville, AL 35652
}

\begin{abstract}
Design and development of a second generation Plasma Pyrolysis Assembly (PPA) reactor is currently underway as part of NASA's Atmosphere Revitalization Resource Recovery effort. By recovering up to $75 \%$ of the hydrogen currently lost as methane in the Sabatier reactor effluent, the PPA helps to minimize life support resupply costs for extended duration missions. To date, second generation PPA development has demonstrated significant technology advancements over the first generation device by doubling the methane processing rate while, at the same time, more than halving the required power. One development area of particular interest to NASA system engineers is fouling of the PPA reactor with carbonaceous products. As a mitigation plan, NASA MSFC has explored the feasibility of using an oxidative plasma based upon metabolic $\mathrm{CO}_{2}$ to regenerate the reactor window and gas inlet ports. The results and implications of this testing are addressed along with the advanced PPA reactor development.
\end{abstract}

\section{Nomenclature}

$\begin{array}{ll}\text { 1stGen } & =\text { first generation } \\ \mathrm{AR} & =\text { atmosphere revitalization } \\ \mathrm{C} & =\text { carbon } \\ \mathrm{CH}_{4} & =\text { methane } \\ \mathrm{CM} & =\text { crew member } \\ \mathrm{CO} & =\text { carbon monoxide } \\ \mathrm{CO}_{2} & =\text { carbon dioxide } \\ \mathrm{CRA} & =\text { Carbon Dioxide Reduction Assembly } \\ \mathrm{H}_{2} & =\text { hydrogen } \\ \mathrm{H}_{2} \mathrm{O} & =\text { water } \\ \mathrm{MSFC} & =\text { Marshall Space Flight Center }\end{array}$

${ }_{1}^{1}$ Senior Engineer, 125 Volunteer Way - P.O. Box 609, rwheeler@urcmail.net, AIAA Member.

${ }^{2}$ Technician, 125 Volunteer Way - P.O. Box 609, nhadley@urcmail.net, Non-Member.

${ }^{3}$ Design Engineer, 125 Volunteer Way - P.O. Box 609, dahl@urcmail.net, Non-Member

${ }^{4}$ Aerospace Engineer, ECLSS Development Branch, MS ES62, AIAA Member.

${ }^{5}$ Aerospace Engineer, ECLSS Development Branch, MS ES62, Non-Member.

${ }^{6}$ Senior Engineer, 8811 Valley View Dr., Huntsville AL, Senior Member.

${ }^{7}$ INSPIRE Intern 2011, P.O. Box 58, lilredlu@ yahoo.com, Non-Member. 


$\begin{array}{ll}\mathrm{O}_{2} & =\text { oxygen } \\ \text { OGA } & =\text { Oxygen Generation Assembly } \\ \text { PPA } & =\text { Plasma Pyrolysis Assembly } \\ \text { SBIR } & =\text { Small Business Innovative Research } \\ \text { sccm } & =\text { standard cubic centimeters per minute } \\ \text { SDU } & =\text { Sabatier Development Unit } \\ \text { SOW } & =\text { statement-of-work }\end{array}$

\section{Introduction}

E FFECTIVE methods for recovery and regeneration of valuable resources are needed to facilitate extended duration manned missions such as a return to the lunar surface or an expedition to Mars. Current technology for recovery of oxygen $\left(\mathrm{O}_{2}\right)$ from carbon dioxide $\left(\mathrm{CO}_{2}\right)$ is embodied in the Carbon Dioxide Reduction Assembly (CRA) ${ }^{1-17}$ The CRA employs a fixed-bed ruthenium-alumina catalytic reactor and molecular hydrogen $\left(\mathrm{H}_{2}\right)$ to reduce $\mathrm{CO}_{2}$ to methane $\left(\mathrm{CH}_{4}\right)$ and water $\left(\mathrm{H}_{2} \mathrm{O}\right)$ via the Sabatier reaction as shown in Eq. (1), where $\mathrm{O}_{2}$ is ultimately recovered via water electrolysis in the Oxygen Generation Assembly (OGA).

$$
\mathrm{CO}_{2}+4 \mathrm{H}_{2} \rightarrow 2 \mathrm{H}_{2} \mathrm{O}+\mathrm{CH}_{4}
$$

In the Sabatier reaction, half of the $\mathrm{H}_{2}$ is lost as $\mathrm{CH}_{4}$. Without additional processing, this $\mathrm{CH}_{4}$ becomes a waste product because no equivalent amount of oxidant is produced, hence $\mathrm{CH}_{4}$ cannot be used as a fuel or propellant unless additional oxygen is provided. Under NASA Phase I and Phase II Small Business Innovative Research (SBIR) contracts, development efforts using microwave plasma pyrolysis techniques were pursued. ${ }^{(18-21)}$ This approach allows for the recovery of up $75 \%$ of the $\mathrm{H}_{2}$ currently lost as $\mathrm{CH}_{4}$ per the acetylene formation reaction shown in Eq. 2.

$$
2 \mathrm{CH}_{4} \rightarrow \mathrm{C}_{2} \mathrm{H}_{2}+3 \mathrm{H}_{2}
$$

This technology was embodied in a first generation Plasma Pyrolysis Assembly (PPA), shown in Figure 1, and subsequently delivered to NASA-Marshall Space Flight Center (MSFC) where it has undergone extensive independent testing as both a stand-alone device and integrated with the Sabatier Development Unit (SDU). ${ }^{22-24}$ The $1^{\text {st }}$ generation (1stGen) PPA, while proving adequate to demonstrate the potential of plasma pyrolysis techniques, falls short of the processing throughput and process efficiencies needed for effective loop closure in application as a $\mathrm{H}_{2}$ recovery, post-processor for the Sabatier reactor. Recent advanced PPA development, however, has led to a second generation evolution of the PPA technology which addresses these shortcomings.

Specific advances in second generation PPA technology include: attaining a full one crew-member $(\mathrm{CM})$ sized $\mathrm{CH}_{4}$ processing capacity (compared to less than $1 / 2-\mathrm{CM}$ scale in the first generation device) while maintaining $90 \% \mathrm{CH}_{4}$ conversion in a single pass configuration; incorporation of a more robust quartz window; addition of a redundant double seal design to promote safe operation;

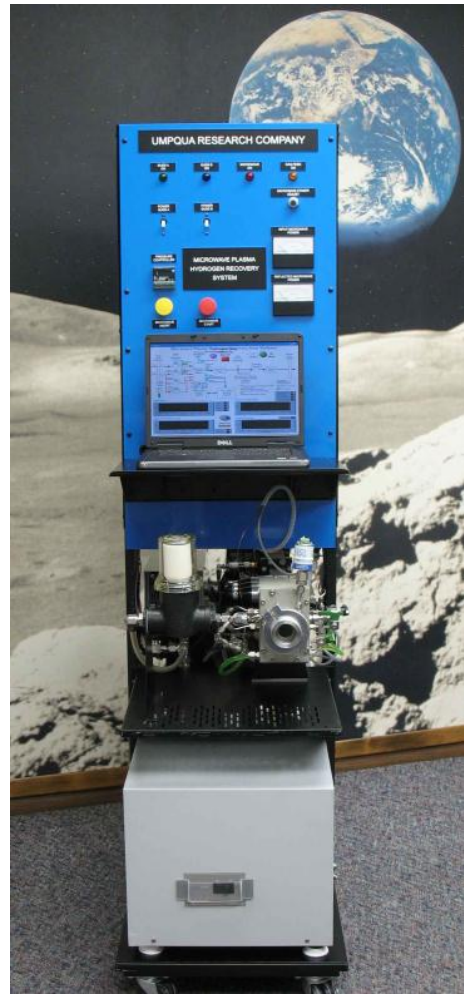

Figure 1. First Generation Plasma Pyrolysis Assembly. reduction in required amount of microwave power required to drive the process as well as reduction in the amount of microwave power wasted in reflections from the reactor; and a corresponding improvement in the specific energy efficiency required for chemical conversion. All this was achieved while maintaining low amounts of carbon production with improved selectivity for acetylene formation. Finally, performance for each reactor design was measured over several hours of operation with successive long duration tests and the relative advantages of each reactor design were identified.

It is believed that the greatest possible risk to long-term efficiency of the PPA is carbonaceous material formation on the quartz window or in the inlet/outlet gas ports. Carbonaceous build-up on the quartz window will eventually inhibit microwave transmission into the reactor, thereby reducing reactor performance. In addition, partial blockage of the gas ports will cause changes to flow dynamics inside the reactor, causing changes to the flow 
paths and corresponding reactor conversion efficiency. For this reason, MSFC performed initial PPA reactor regeneration testing, concurrent with advanced PPA reactor development work, to determine the feasibility of using $\mathrm{CO}_{2}$, a gas already readily available in the Atmosphere Revitalization (AR) loop, to remove accumulated carbon and carbonaceous build-up via the Reverse-Boudouard reaction:

$$
\mathrm{CO}_{2}+\mathrm{C} \rightarrow 2 \mathrm{CO}
$$

Classically, this reaction only occurs at elevated temperature $\left(>700{ }^{\circ} \mathrm{C}\right)$. The method developed here, however, utilizes the microwave chamber to create a $\mathrm{CO}_{2}$ plasma in situ (in place of the $\mathrm{H}_{2} / \mathrm{CH}_{4}$ plasma present during methane plasma pyrolysis). Highly reactive species produced in the $\mathrm{CO}_{2}$ plasma are then available to oxidize carbon compounds as they impinge upon coated surfaces via both forced and natural convection along with slower molecular diffusion. PPA Regeneration testing at MSFC included testing to prove the feasibility of igniting a $\mathrm{CO}_{2}$ plasma, the feasibility of the $\mathrm{CO}_{2}$ plasma resulting in the Reverse-Boudouard reaction, and the effect of reactor operating parameters on the relative level of regeneration.

\section{Advanced PPA Reactor Design}

The design effort began by reviewing the 1stGen reactor development work and performance results. Specific performance improvement goals were outlined in the Statement Of Work (SOW) for the Advanced PPA reactor. Targeted improvements included greater quartz window stability, more robust vacuum seal integrity, reduced carbon formation, increased energy efficiency, higher methane conversion, and improved acetylene selectivity all at a full 1-CM scale $(400 \mathrm{sccm}) \mathrm{CH}_{4}$ processing rate. Conceptual designs for two 1-CM scale advanced plasma reaction chambers were developed to achieve these objectives. Detailed designs were prepared for a Low-Risk reactor, which built upon the core design of the first generation device, and a Higher-Risk reactor, which employed novel features offering potentially much greater performance. The two reactors were subsequently fabricated using CNC milling techniques.

By critically considering both the positive and negative aspects of the various design iterations evaluated during development of the 1stGen PPA, key design aspects were identified. Along with the internal dimensions of the reactor, the presence and location of a plasma locating stub were determined to arguably be the most important design elements that impact process throughput, methane conversion efficiency, and energy efficiency. Factors impacting the nature and quantity of carbonaceous compounds formed in the reactor during testing were also identified. The $\mathrm{H}_{2}$ to $\mathrm{CH}_{4}$ feed ratio entering the PPA has the most significant impact on the amount and nature of condensed carbon compounds formed in the reactor over time. High $\mathrm{H}_{2}$ to $\mathrm{CH}_{4}$ ratios yield the least solids buildup, but the carbonaceous coatings that do form are of a brittle nature and difficult to remove from the reactor walls by mechanical action. Conversely, low $\mathrm{H}_{2}$ to $\mathrm{CH}_{4}$ ratios produce more solids, but this material is light and powdery in nature, making it relatively manageable via manual cleaning. Long duration testing at MSFC ( $>45$ hours) using a nominal 4:1, $\mathrm{H}_{2}: \mathrm{CH}_{4}$ molar feed ratio demonstrated low solids production for the 1 stGen PPA.

\section{A. Design Goals}

Specific process performance improvement targets were identified in the Phase 3 SOW for the Advanced PPA reactor technology. These performance goals are presented in Table 1 and compared to the demonstrated performance of the 1stGen PPA.

Table 1. Performance improvement goals for an advanced PPA Reactor.

\begin{tabular}{|c|c|c|}
\hline Parameter & $\begin{array}{c}1^{\text {st }} \text { Generation Reactor } \\
\text { Performance }\end{array}$ & $\begin{array}{c}\text { Advanced Reactor } \\
\text { Targets }\end{array}$ \\
\hline Microwave Power & $700 \mathrm{~W}$ & $\leq 350 \mathrm{~W}$ \\
\hline Energy Efficiency@400sccm & $6.20 \%$ & $\geq 25 \%$ \\
\hline$\% \mathrm{CH}_{4}$ Conversion@ 400sccm & $80 \%$ & $\geq 90 \%$ \\
\hline $\mathrm{CH}_{4}$ Throughput @ 90\% $\mathrm{CH}_{4}$ Conversion & $160 \mathrm{sccm}$ & $\geq 400 \operatorname{sccm}(1 \mathrm{CM})$ \\
\hline $\begin{array}{l}\text { Acetylene Selectivity (\% of carbon from } \\
\text { converted } \mathrm{CH}_{4} \text { ) @ 400sccm }\end{array}$ & $62 \%$ & $\geq 75 \%$ \\
\hline
\end{tabular}


In addition to modifications that yield greater reactor performance, design alterations that make an advanced reactor safer and more robust were also sought out. Periodic failure of the quartz window (cracking along centerline through the narrow dimension) proved to be the single most important factor limiting test duration. This phenomenon is most likely related to the thermal stresses created within the quartz by the close proximity of the hot reactive plasma volume, which heats the center of the quartz window via both conductive and radiative heat transfer, and the relatively cold contact boundary between the window and the actively cooled metal walls. As such, thicker $(\Delta \mathrm{z})$, more robust quartz windows that better withstand the temperature and pressure extremes experienced in a PPA reactor, were utilized in all designs considered during this advance development effort. In addition, these windows were also made larger in their $\mathrm{x}$ and $\mathrm{y}$ dimensions so as to support a double seal configuration for multilayer leak protection. While a rare event, the 1stGen PPA reactor with a single o-ring design did experience a minor air leak during at least one test at MSFC. By adding a second concentric seal, inherent system safety is significantly improved.

\section{B. Low-Risk Reactor}

The concept for the Low-Risk reactor consisted of key improvements to the 1 stGen PPA reactor. This reactor would not only facilitate evaluation and verification testing of next generation design improvement concepts such as number and location of methane feed jets, removal of the window sweep plate, and reduction or elimination of the hydrogen feed stub/plasma locator nozzle, but also potentially serve as the deliverable reactor if sufficient performance gains were made. This reactor is shown in Figure 2.

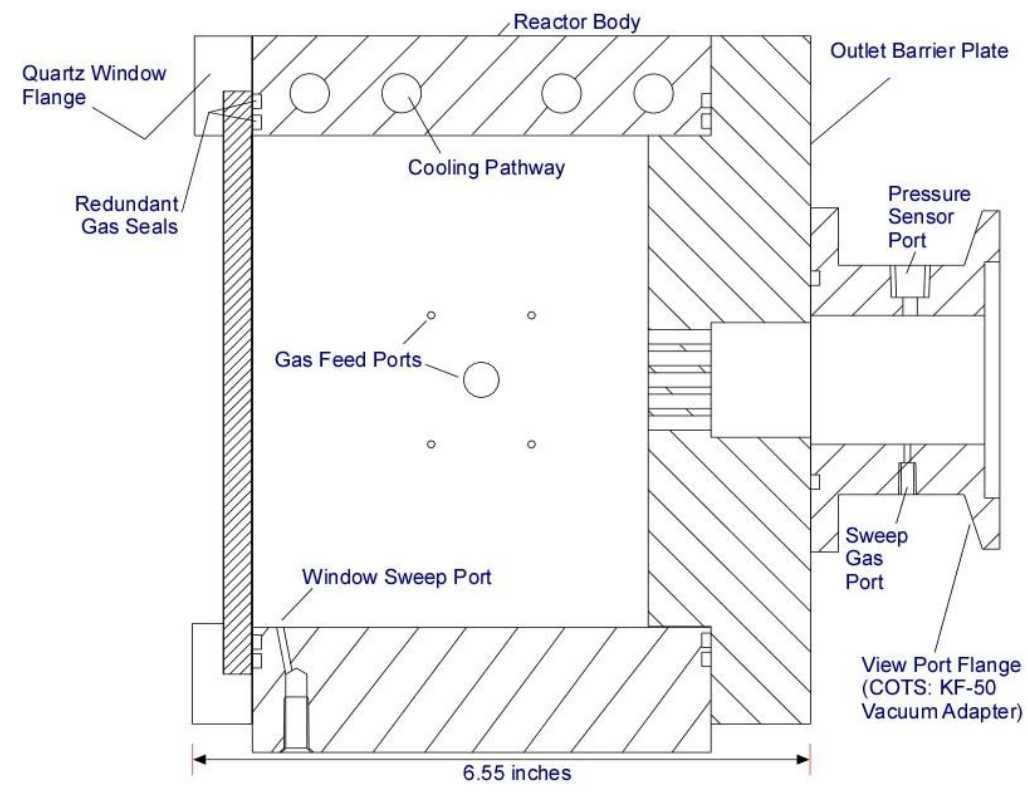

Figure 2. Low-risk advanced PPA reactor design.

\section{Higher-Risk Reactor}

For the Higher-Risk reactor, more risky design concepts were envisioned, which also offered potentially greater reactor performance gains. Firstly, the quartz window was moved farther from the hot plasma, thereby protecting it from thermal degradation. Secondly, a smaller reactor cross-section was utilized which served to concentrate microwave power density and the corresponding plasma density thus requiring less power to attain pyrolysis reaction conditions. This reactor is shown in Figure 3.

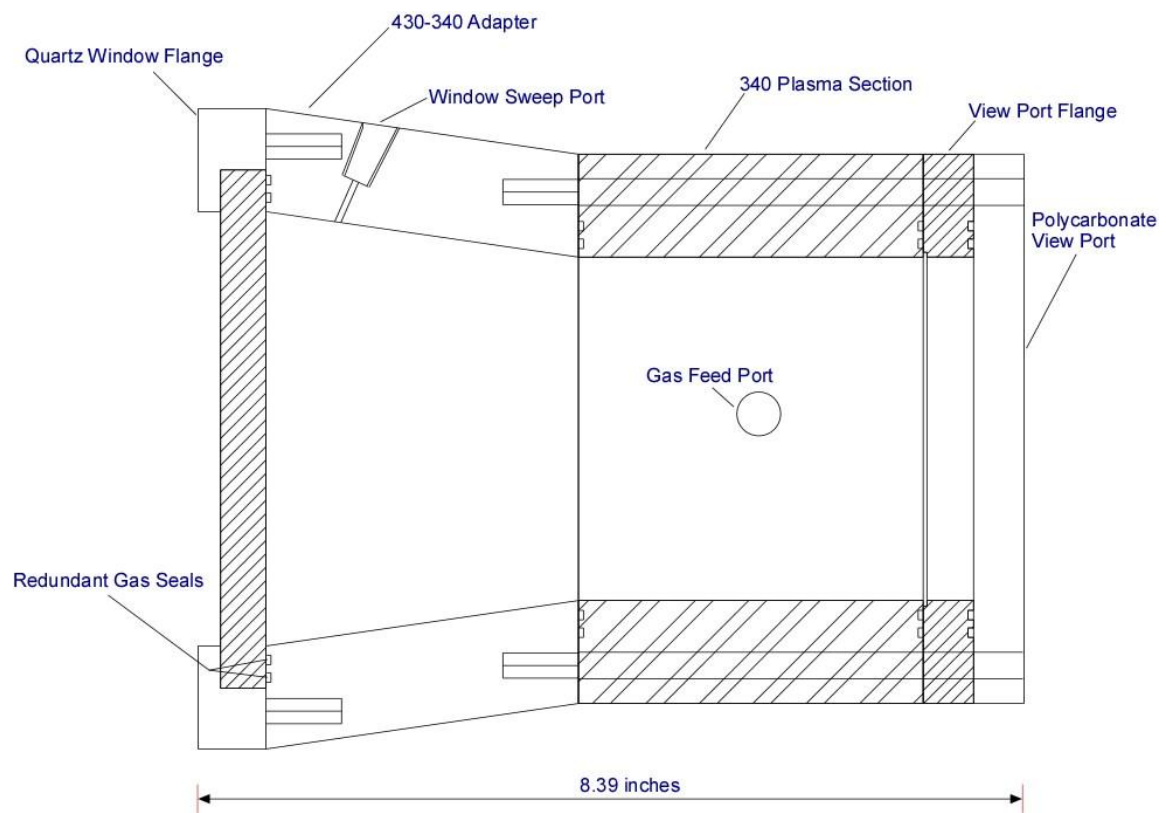

Figure 3. Higher-Risk advanced PPA reactor design. 


\section{Advanced Reactor Performance Testing}

Each of the advanced PPA reactors was challenged with a variety of performance tests. These tests were designed to evaluate each reactor's process performance and help identify their unique operational characteristics. Performance testing for each advanced reactor culminated in back-to-back nominal 8-hour tests demonstrating feasibility for long-term operational stability. Testing with each reactor is discussed below.

\section{A. Low-Risk Reactor}

Photos of the advanced PPA Low-Risk reactor taken during plasma pyrolysis and between tests are shown in Figure 5. The Low-Risk reactor integrated into the PPA test stand is shown in Figure 4.

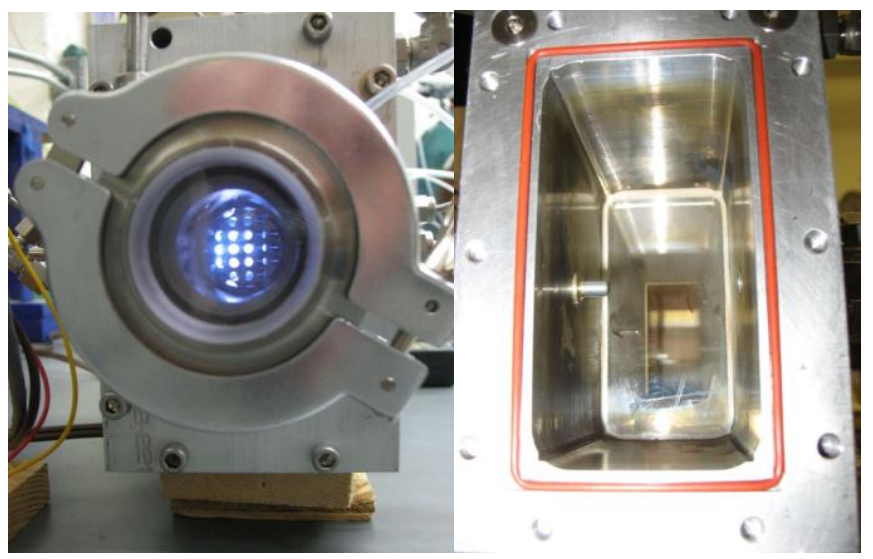

Figure 5. Low-Risk reactor. Reactor plasma during methane pyrolysis (left photo) and with the chamber end-plate removed prior to test (right photo).

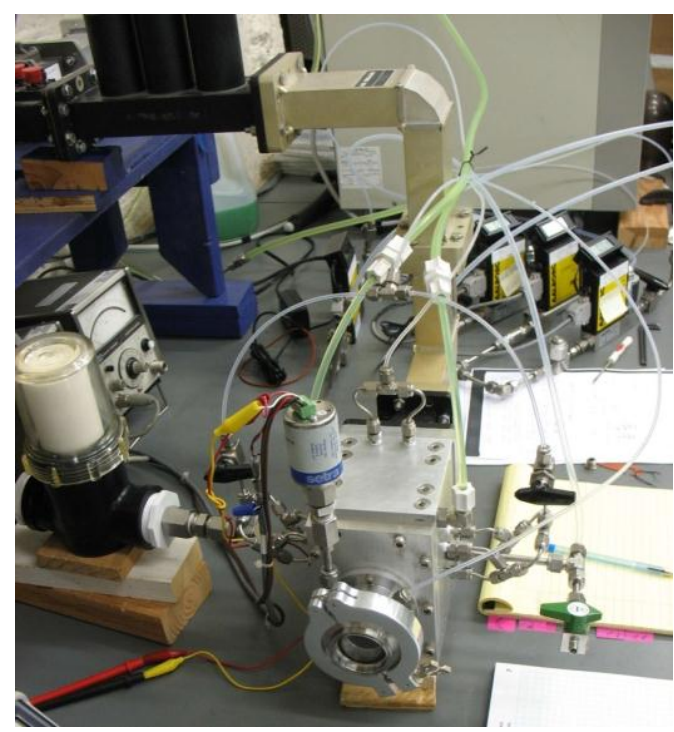

Figure 4. Advanced PPA Low-Risk reactor and test stand. Reactor integrated into test stand and ready for pyrolysis testing.
Using an 11/32 inch stub located on the reactor outlet port, two successive, long-duration tests were performed with a $26 \% \quad \mathrm{CH}_{4}$ feed concentration at microwave power and process pressure levels of $315 \mathrm{~W}$ and 50 Torr, respectively. The result of the second back-to-back run is shown in Figure 6. Methane conversions over the course of these long duration tests were just over the targeted 90\% level with a $\mathrm{H}_{2}$ recovery just under $70 \%$. This level of $\mathrm{H}_{2}$ recovery corresponds directly to stoichiometric acetylene production as per Eq. (2) above, since $67.5 \%$ recovery is expected at $90 \%$ conversion. In addition, note that microwave power absorbed by the plasma remained above $98 \%$ for the duration of these tests. This high degree of microwave power to plasma heating conversion efficiency is the direct result of the welltuned single mode cavity design. Microwave energy to chemical conversion energy efficiency was $17 \%$ for each test.

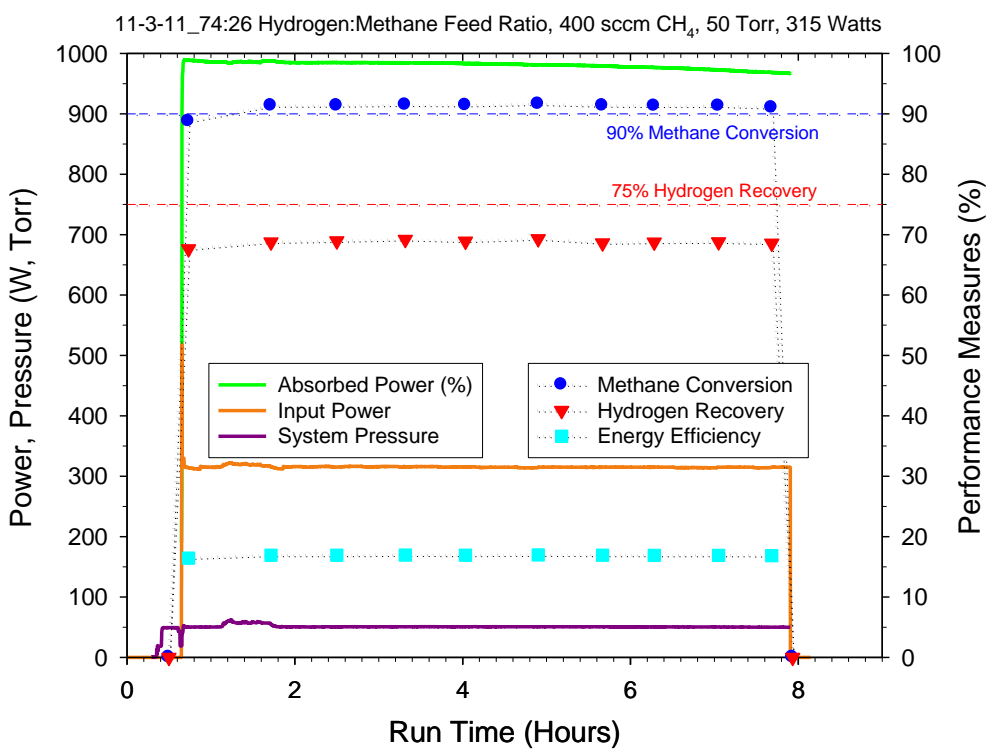

Figure 6. Second Advanced PPA Low-Risk Reactor long-duration performance test. Test conducted at $400 \mathrm{sccm}, 26 \mathrm{~mol} \%$ methane, 50 Torr, and $315 \mathrm{~W}$ for $7 \mathrm{hrs}$.

American Institute of Aeronautics and Astronautics 


\section{B. Higher-Risk Reactor}

The Higher-Risk advanced PPA reactor is shown in Figure 7 while integrated into the PPA test stand. Forced air cooling of the reactor was found to be inadequate so copper cooling plates were attached to the outside of the reactor. The perforated plate viewport permits observation of the 3-dimensional behavior of the plasma within the reactor as seen in Figure 8. This viewing capability was found to be critical for developmental testing, allowing rapid process trouble-shooting and immediate feedback on the effects of changing process variables such as power, pressure and flow rate.

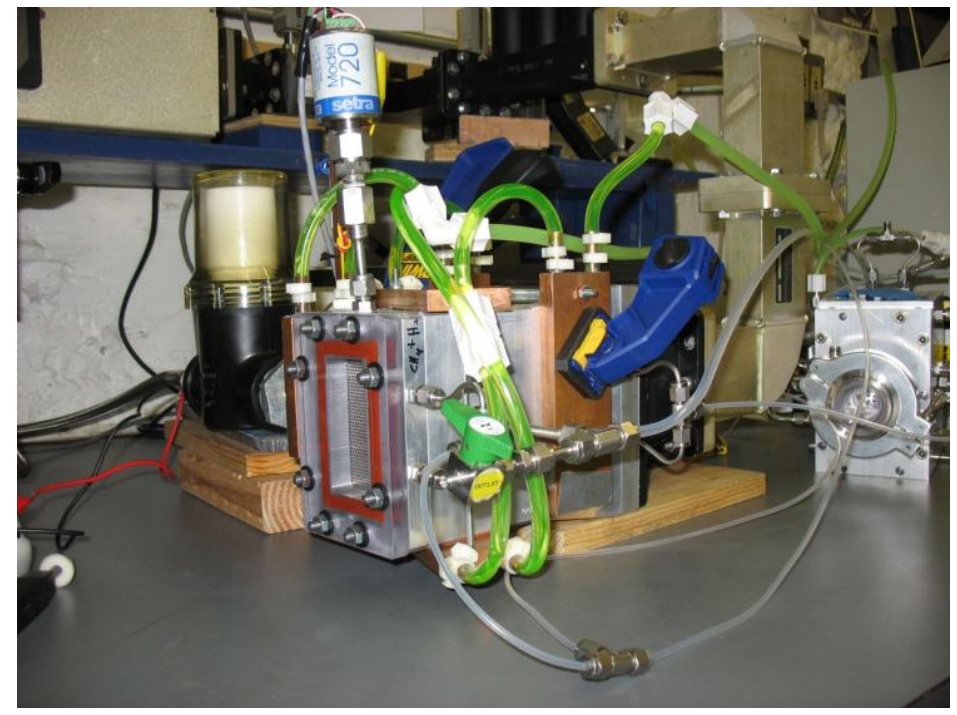

Figure 7. Advanced PPA Higher-Risk reactor fitted with external cooling plates prior to first pyrolysis test.

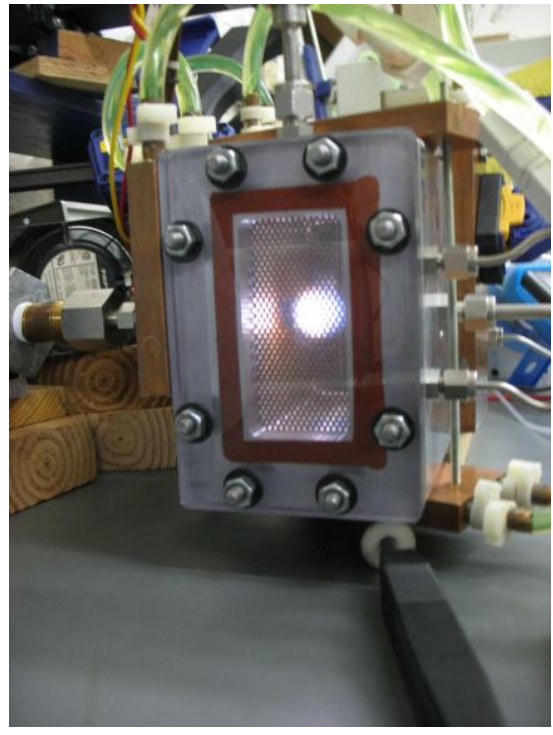

Figure 8. Higher-Risk reactor in operation with $5 / 16$ inch stub at 100 Torr and $370 \mathrm{~W}$.
Two successive, long-duration tests were performed using the Higher-Risk reactor operating at a $26 \%$ methane feed at $400 \mathrm{sccm}$, a microwave power of $320 \mathrm{~W}$, and a process pressure of 70 Torr. The result of the second of the back-to-back runs is shown in Figure 9. Methane conversions for both runs were over $90 \%$ with energy conversion efficiency at $17 \%$. Hydrogen recovery for the Higher-Risk reactor was typically just under $70 \%$ for the majority of each test which was similar to that observed for the LowRisk reactor (compare plot in Figure 9 to that in Figure 6). Absorbed microwave power was somewhat less than the $98 \%$ observed for the LowRisk reactor, but nevertheless remained over $95 \%$, which is still indicative of a well-tuned reactor. Both the Low-Risk reactor and the Higher-Risk reactor appear to have very similar performances with the obvious operational difference between the two being the required operating pressure (50 Torr for the Low-Risk reactor and 70 Torr for the Higher-Risk reactor).

6

American Institute of Aeronautics and Astronautics 


\section{Performance Summary}

Second generation PPA reactor development has thus far demonstrated significant technology advancements over the 1stGen reactor as summarized in Table 2. Both advanced reactors have more than doubled the methane processing rate to a full $400 \mathrm{sccm}, 1-\mathrm{CM}$ scale while, at the same time, more than halving the required microwave power, going from $700 \mathrm{~W}$ to $\leq 320 \mathrm{~W}$. Importantly, these performance gains have been attained while also improving the single-pass $\mathrm{CH}_{4}$ conversion efficiency from $80 \%$ to over $90 \%$. Despite near optimal utilization (>98\%) of the microwave power by the plasma to create excited plasma species, the net microwave energy to chemical energy efficiency for conversion of $\mathrm{CH}_{4}$ to acetylene and $\mathrm{H}_{2}$ nevertheless remained around $17 \%$ during performance testing with either of the advanced reactors. While significantly better than the $6 \%$ demonstrated by the 1stGen PPA reactor, $17 \%$ remains somewhat below the $25 \%$ level targeted in our advanced PPA development work and well below the best value of $62 \%$ reported in the scientific literature. ${ }^{25}$ While somewhat disappointing, this shortfall may well be an inherit design limitation that is related to the geometric aspects of these advanced PPA reactor designs (i.e., 17\% may be the performance wall for these types of designs at 50 Torr). Alternatively, since energy efficiency has been observed to be dependent on operating pressure and $\mathrm{CH}_{4}$ flow (reaching as high as $22 \%$ during Low-Risk reactor performance testing at 77 Torr, $800 \mathrm{sccm}$ and $25 \% \mathrm{CH}_{4}$ ), the $25 \%$ first year goal or even the $62 \%$ best value goal may be attainable under the right pressure, total flow, and $\mathrm{CH}_{4}$ conversion conditions. The final performance parameter listed in Table 2, acetylene selectivity, was improved from $62 \%$ for the first generation PPA well beyond the targeted $75 \%$ to $\geq 86 \%$ for the advanced PPA reactors.

Table 2. Performance improvements for advanced PPA reactors.

\begin{tabular}{|c|c|c|c|c|}
\hline Parameter & $\begin{array}{l}1^{\text {st }} \text { Generation } \\
\text { Reactor } \\
\text { Performance }\end{array}$ & $\begin{array}{c}\text { Advanced } \\
\text { Reactor Targets }\end{array}$ & $\begin{array}{l}\text { Low-Risk reactor } \\
\text { Performance (@ } \\
50 \text { Torr) }\end{array}$ & $\begin{array}{c}\text { Higher-Risk reactor } \\
\text { Performance (@70 } \\
\text { Torr) }\end{array}$ \\
\hline Microwave Power & $700 \mathrm{~W}$ & $\leq 350 \mathrm{~W}$ & $315 \mathrm{~W}$ & $\leq 350 \mathrm{~W}$ \\
\hline Energy Effíciency@ 400sccm & $6.2 \%$ & $\geq 25 \%$ & $16.9 \%$ & $16.8 \%$ \\
\hline \% $\mathrm{CH}_{4}$ Conversion@ 400sccm & $\mathbf{8 0} \%$ & $\geq 90 \%$ & $91 \%$ & $92 \%$ \\
\hline $\begin{array}{c}\mathrm{CH}_{4} \text { Throughput @ } 90 \% \mathrm{CH}_{4} \\
\text { Conversion }\end{array}$ & $160 \mathrm{sccm}$ & $\begin{array}{l}\geq 400 \mathrm{sccm} \\
(1 \mathrm{CM})\end{array}$ & $400 \mathrm{sccm}$ & $400 \mathrm{sccm}$ \\
\hline $\begin{array}{l}\text { Acetylene Selectivity }(\% \text { of } \\
\left.\text { carbon from converted } \mathrm{CH}_{4}\right) @ \\
400 \text { scem }\end{array}$ & $62 \%$ & $\geq 75 \%$ & $>86 \%$ & $>87 \%$ \\
\hline
\end{tabular}

\section{Advanced PPA Process Development}

Long-term operation of a PPA in flight application is expected to be limited by the effects of carbonaceous buildup, as mentioned previously. To mitigate this concern, PPA Regeneration testing was completed on the PPA Test Stand at MSFC's Environmental Control and Life Support Systems Development Facility. For this effort, the 1 stGen reactor was used as integrated into the PPA at MSFC, as shown in Figure 1. The PPA was developed at UMPQUA Research Co. and delivered to MSFC in 2009 as part of a Phase II SBIR contract. Regeneration testing of the 1stGen reactor involved three testing phases at MSFC and an implementation phase at UMPQUA as described below.

Phase I was completed to determine the parameters necessary for igniting a $\mathrm{CO}_{2}$ plasma in the PPA. A full factorial parametric test was completed with $\mathrm{CO}_{2}$ feed rates of 50,200, and $500 \mathrm{sccm}$ and reactor pressures of 15 , 30, or 45 Torr. This test was replicated three times.

Phase II testing was completed to determine the feasibility of removing accumulated PPA carbon with a $\mathrm{CO}_{2}$ plasma, thereby forming CO. Testing was completed in a series of two-day trials. The first day of each trial was dedicated to accumulating carbon for 6 hours with $200 \mathrm{sccm}$ of $\mathrm{CH}_{4}$ and a total of $800 \mathrm{sccm}$ of $\mathrm{H}_{2}$ continuously fed to the reactor. The system was operated at total reactor pressure of 45 Torr and a microwave power setting of 600 $\mathrm{W}$. The second day of each trial was dedicated to regeneration for 15 minutes, 30 minutes, or 2 hours at $100 \mathrm{sccm}$ $\mathrm{CO}_{2}$ flow rate, a reactor pressure of 45 Torr and $600 \mathrm{~W}$ microwave power. At the end of each regeneration cycle, the reactor was photographed before the remaining carbonaceous product was mechanically removed from the reactor surfaces and weighed. During mechanical removal of residual carbon, the quartz window was left untouched to protect the surface. 
Phase III testing was completed to determine the effects of pressure, microwave power, and $\mathrm{CO}_{2}$ flow rate on PPA regeneration. For each trial, carbon was accumulated for 6 hours as described in Phase II testing. Each regeneration trial was conducted for 20 minutes from the moment of $\mathrm{CO}_{2}$ plasma ignition. Tested reactor pressures included 20,35, and 50 Torr. Tested $\mathrm{CO}_{2}$ flow rates included 100, 200, and $500 \mathrm{sccm}$. Tested microwave powers included 400,500, and 600W. A single replicate was completed for each data point.

Test results from MSFC's development work of the $\mathrm{CO}_{2}$ plasma cleaning step were applied to cleaning the advanced PPA reactors between selected discrete performance evaluation tests. In particular, for the Higher-Risk reactor, a regularly scheduled $\mathrm{CO}_{2}$ plasma cleaning step was used after each nominal 8 hours of methane pyrolysis.

\section{A. Phase I PPA Regeneration Test Results}

Using the 1stGen PPA reactor, a $\mathrm{CO}_{2}$ plasma was reliably ignited at a reactor pressure of 15 Torr regardless of the $\mathrm{CO}_{2}$ flow rate, as shown in Figure 10. However, the power required to ignite the plasma varied dramatically from run to run. There was no significant difference in power required for ignition with respect to $\mathrm{CO}_{2}$ flow rate. At 30 Torr, ignition of the $\mathrm{CO}_{2}$ plasma was shown to be possible; however, ignition was unreliable and often required multiple attempts. At the $50 \mathrm{sccm}$ and $200 \mathrm{sccm} \mathrm{CO}$ flow rates, the plasma was only ignited in two of the three replicates. At the $500 \mathrm{sccm} \mathrm{CO}_{2}$ flow rate, the plasma was only ignited in one

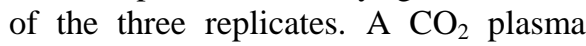
could not be ignited at 45 Torr.

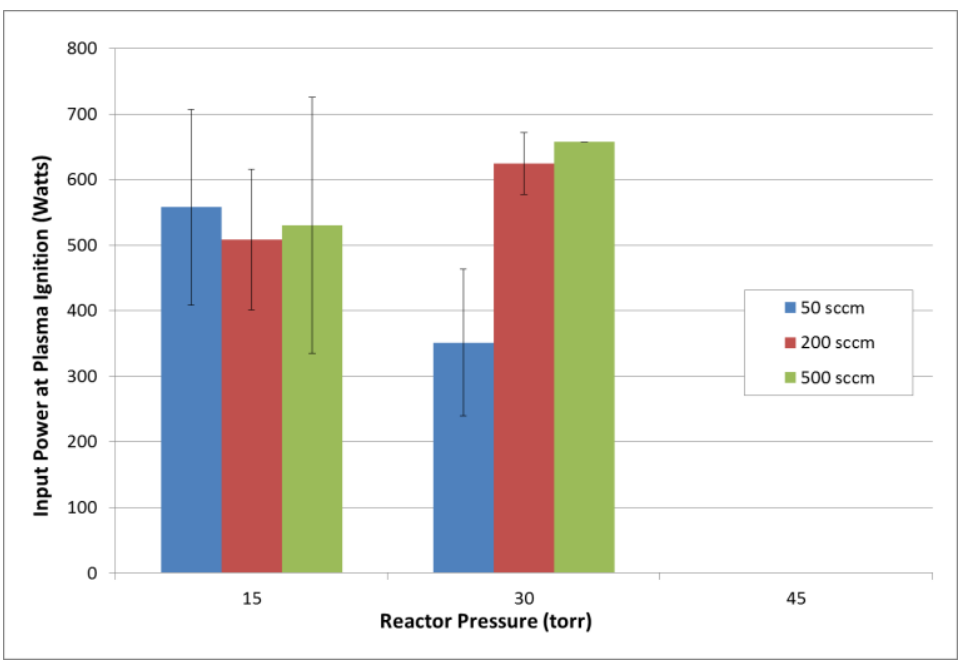

Figure 10. Average Input Power vs. Pressure for $\mathrm{CO}_{2}$ plasma ignition.

Based on these findings, it is clear that the reactor pressure will need to be below 30 Torr to reliably and repeatedly ignite a $\mathrm{CO}_{2}$ plasma. For long duration missions, PPA regeneration capability may be necessary. However, constraining the design of the system vacuum pump to accommodate these low pressures may not be as advantageous as simply replacing the quartz window or entire reactor chamber. Future trade analyses are planned to explore these options.

\section{B. Phase II PPA Regeneration Test Results}

Following a six hour carbon accumulation, the first generation PPA reactor was regenerated for 15 minutes, 30 minutes, or 2 hours. As shown in Figure 11 , the majority of the carbonaceous product was removed in the first 15 minutes of the regeneration cycle. Due to these findings, a second test was run in which the reactor accumulated carbon for 18 hours, followed by a 15 minute $\mathrm{CO}_{2}$ regeneration cycle. Photos a, b, c, and $\mathrm{d}$ in Figure 12 show the carbon accumulation on the quartz window over 6, 12, and 18 hours (photos a, b, and c, respectively) and the effect of the relatively short regeneration cycle (photo d). This data suggest that as long as the inlet/outlet ports are not blocked, very short regeneration cycles will be sufficient to maintain a clean quartz window. It should also be noted that no decrease in performance was observed

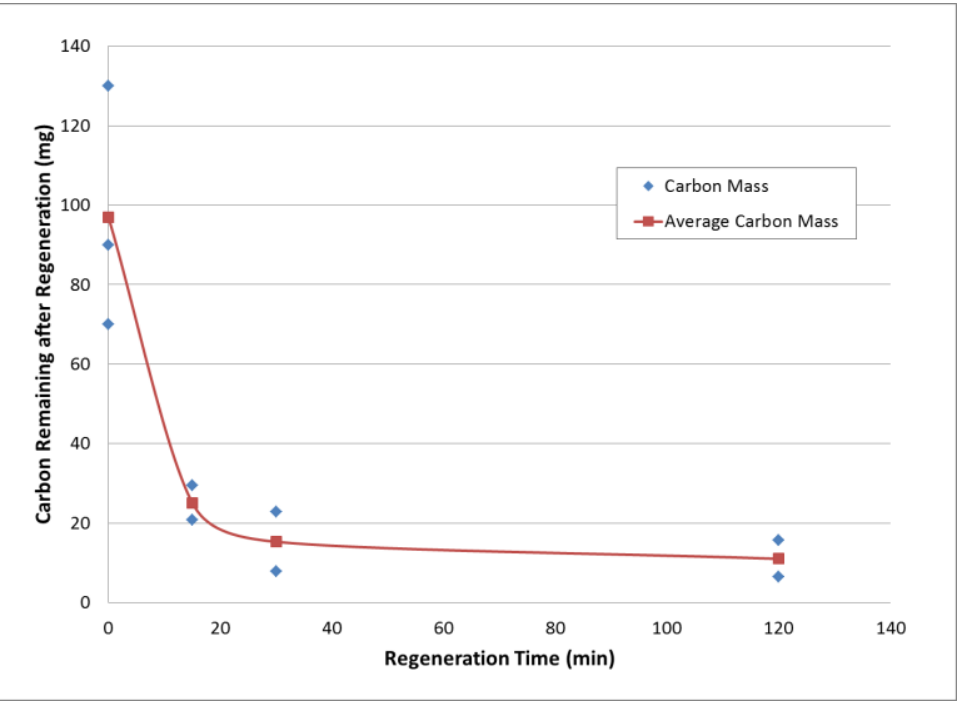

Figure 11. PPA Carbon Removal via $\mathrm{CO}_{2}$ Plasma.

American Institute of Aeronautics and Astronautics 
after 18 hours of carbon accumulation suggesting that regeneration cycles may be performed at much longer intervals than originally believed. Another important consideration for advanced PPA reactor development is that
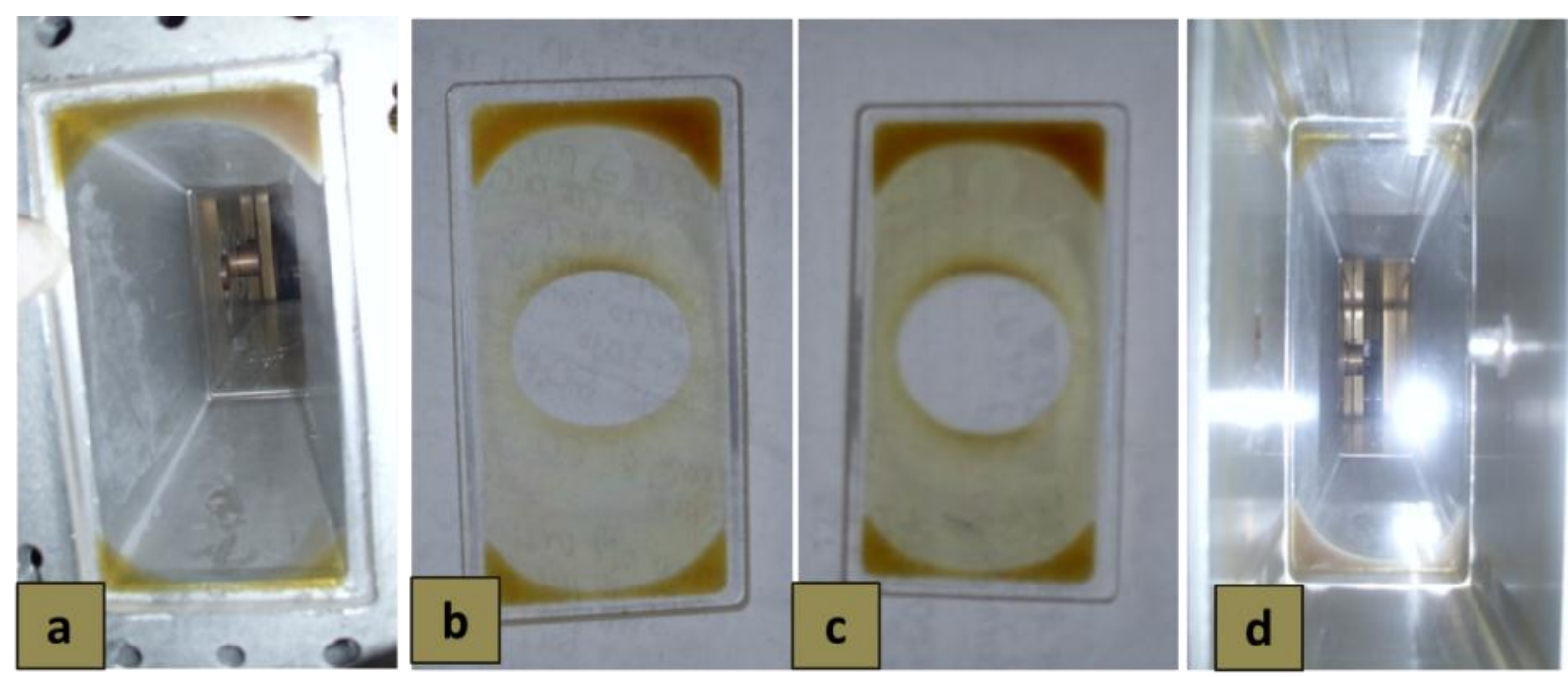

Figure 12. PPA reactor quartz window after a) 6 hours, b) 12 hours, and c) 18 hours of carbon accumulation. Also shown is d) the window after a 15 minute regeneration cycle.

placement of the plasma inside the reactor may well have a significant influence on the quartz window regeneration. As such, redesign of the reactor chamber may alter the location of this plasma, thus changing the localized effect of $\mathrm{CO}_{2}$ regeneration on the quartz window.

\section{Phase III PPA Regeneration Test Results}

Phase III testing was completed to investigate the influence of reactor pressure, microwave power, and $\mathrm{CO}_{2}$ flow rate on the relative reactor regeneration performance. Although only one replicate was completed for this testing, images of the inside of the

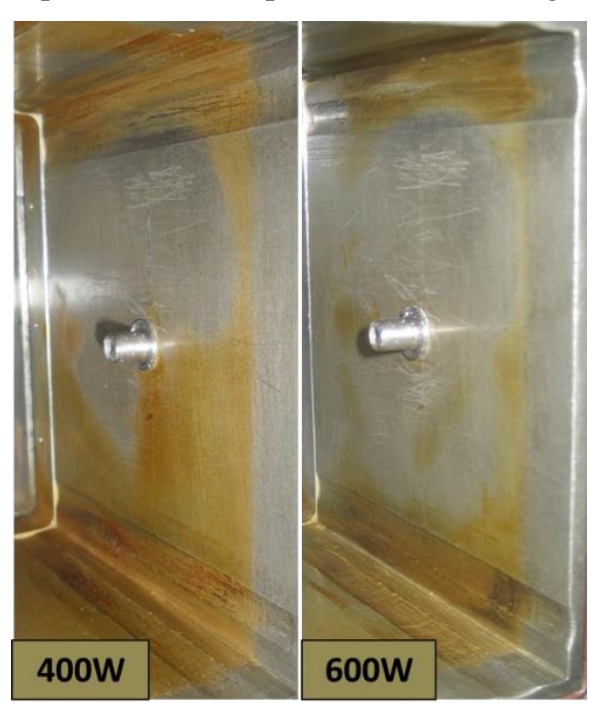

Figure 13. Microwave power effect on PPA regeneration. Regeneration completed with 50 torr and $500 \mathrm{sccm}$ $\mathrm{CO}_{2}$ flow at either $400 \mathrm{~W}$ or $600 \mathrm{~W}$.
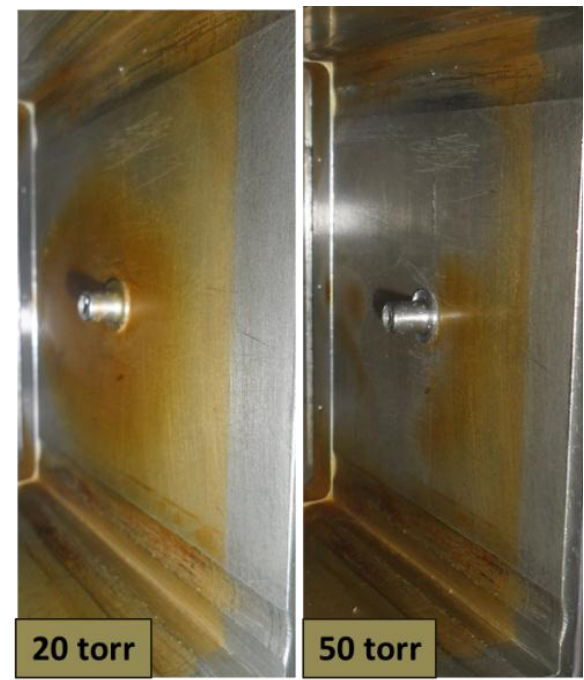

of the plasma stub, strongly suggest that pressure is the factor most influencing regeneration performance. This can be seen in the examples in Figure 14 at 20 and 50 Torr, each operating at $400 \mathrm{~W}$ and $100 \mathrm{sccm}$ $\mathrm{CO}_{2}$ flow. Over the ranges tested, microwave power appeared also to have an effect on regeneration

\section{Figure 14. Pressure effect on PPA} regeneration. Regeneration completed with $400 \mathrm{~W}$ and $100 \mathrm{sccm} \mathrm{CO}_{2}$ flow at either 20 Torr or 50 Torr.

performance, though less influential than pressure. This is shown in the examples in Figure 13 at 400 and $600 \mathrm{~W}$, each operating at 50 Torr and $500 \mathrm{sccm} \mathrm{CO}_{2}$ flow. $\mathrm{CO}_{2}$ flow rate variations appeared to have no effect. 


\section{Advanced PPA Reactor Regeneration Implementation Results}

Test results from MSFC's development work of the $\mathrm{CO}_{2}$ plasma cleaning step were applied to cleaning the advanced PPA reactors between selected discrete performance evaluation tests. In particular, for the Higher-Risk reactor, a regularly scheduled $\mathrm{CO}_{2}$ plasma cleaning step was used after each nominal 8 hours of methane pyrolysis. Before, during (plasma), and after photos of the reactor are shown in Figure 15. Note the color difference between this $\mathrm{CO}_{2}$ plasma and the $\mathrm{H}_{2} / \mathrm{CH}_{4}$ plasma seen in Figure 8; the $\mathrm{CO}_{2}$ plasma appearing as a light blue. The before and after chamber photos located in Figure 16 and Figure 17, respectively, show that most of the carbon build-up around the outlet stub is removed during the $\mathrm{CO}_{2}$ plasma cleaning step. Preferential cleaning of the upper half compared to the lower half is clearly evident. This is presumably due to gravity-driven natural convective flow of hot reactive gases produced during cleaning (in the presence of colder feed gas flow). As such, in the absence of gravity, more symmetrical cleaning about the outlet stub would be expected, except as moderated by gas flow dynamics within the reactor, which are related to both geometry and magnitude of flow. Clearly, while not removing all carbon buildup in the reactor, significant cleaning was observed. A thorough evaluation of this periodic cleaning technique would require several weeks or months' worth of PPA testing where the impact of any long term persistent (un-removed) carbon deposition on reactor performance would be determined.

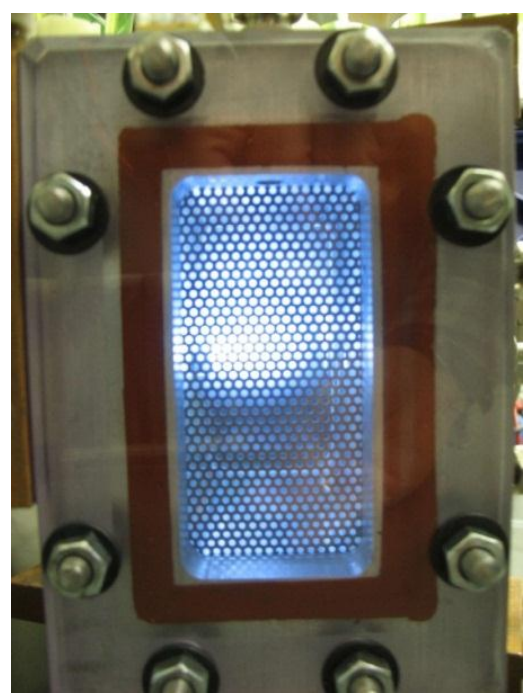

Figure 15. $\mathrm{CO}_{2}$ Plasma Cleaning.

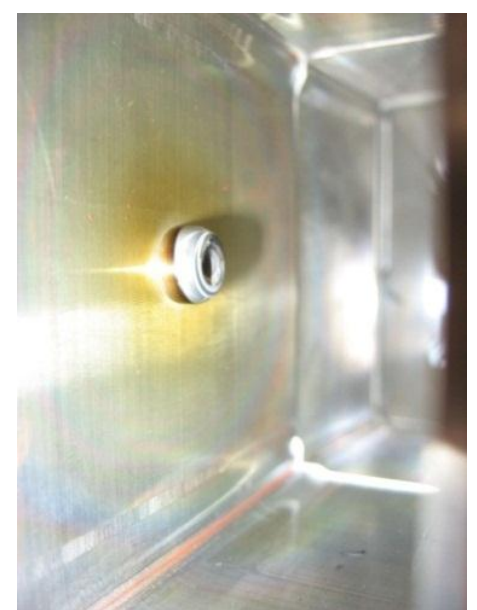

Figure 16. Higher-Risk reactor before cleaning for 32 minutes at 90 Torr, $320 \mathrm{~W}$, and $400 \mathrm{sccm} \mathrm{CO}_{2}$.

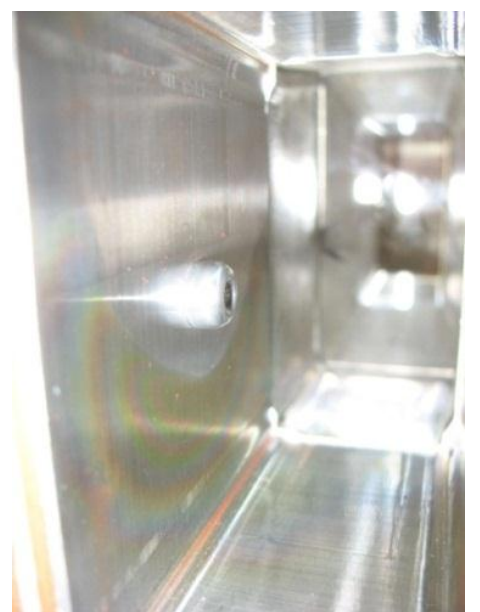

Figure 17. Higher-Risk reactor after cleaning for 32 minutes at 90 Torr, $320 \mathrm{~W}$, and $400 \mathrm{sccm} \mathrm{CO}_{2}$.

\section{Conclusion}

In summary, second generation PPA development has demonstrated significant technology advancements over the 1stGen device by more than doubling the methane processing rate to 1-CM scale while, at the same time, requiring less than half the power. Advanced PPA process development work was performed by personnel at NASA MSFC concurrent with the advanced PPA reactor development effort. Here, an in-situ technique that utilized a $\mathrm{CO}_{2}$ plasma was used to periodically remove carbonaceous material byproducts that naturally accumulate in the reactor over time as a result of non-equilibrium methane pyrolysis. This work represents interim results of an on-going Phase 3 development project. Second year work will focus on scaling to a 4-CM design while further improving PPA performance.

\section{Acknowledgments}

Authors would like to acknowledge NASA's Exploration Technology Development Project for MSFC project funding and contract funding for SBIR Contract NNM1AA34C, and NASA's NSPIRES program for internship funding. Special thanks to Tom Williams for software support, Kenny Bodkin for technical support, and Matt Mansell for chemical analysis support. 


\section{References}

1 Murdoch, K., Fort, J., Barone, M., and Holder, D., Rotary Drum Separator and Pump for the Sabatier Carbon Dioxide Reduction System, SAE Paper No. 2005-01-2863, presented $35^{\text {th }}$ International Conference on Environmental Systems, 2005

2 Knox, J.C., Campbell, M., Murdoch, K., Miller, L.A., and Jeng, F., Integrated Test and Evaluation of a 4-Bed Molecular Sieve (4BMS) Carbon Dioxide Removal System (CDRA), Mechanical Compressor Engineering Development Unit (EDU), and Sabatier Engineering Development Unit (EDU), SAE Paper No. 2005-01-2864, presented 35 ${ }^{\text {th }}$ International Conference on Environmental Systems, 2005..

3 Alptekin, G., Hitch, B., Dubovik, M., Lind, J., and Smith, F., Prototype Demonstration of the Advanced $\mathrm{CO}_{2} \mathrm{Removal}^{\mathrm{n}}$ Reduction System, SAE Paper No. 2005-01-2862, presented $35^{\text {th }}$ International Conference on Environmental Systems, 2005.

4 Murdoch, K., Smith, F., Perry, J., and Green, S., Assessment of Technology Readiness Level of a Carbon Dioxide Reduction Assembly (CRA) for Use on International Space Station, SAE Paper No. 2004-01-2446, presented $34^{\text {th }}$ International Conference on Environmental Systems, 2004.

5 Alptekin, G., Copeland, R., DeVoss, S., Lind, J., and Smith, F., An Advanced $\mathrm{CO}_{2}$ Removal and Reduction System, SAE Paper No. 2004-01-2445, presented 34 ${ }^{\text {th }}$ International Conference on Environmental Systems, 2004.

6 Jeng, F.F., Lafuse, S., Smith, F.D., Lu, S.-D., Knox, J.C., Campbell, M.L., Scull, T.D., and Green, S., Analyses of the Integration of Carbon Dioxide Removal Assembly, Compressor, Accumulator and Sabatier Carbon Dioxide Reduction Assembly, SAE Paper No. 2004-01-2496, presented 34 ${ }^{\text {th }}$ International Conference on Environmental Systems, 2004.

7 Murdoch, K., Perry, J., and Smith, F., Sabatier Engineering Development Unit, SAE Paper No. 2003-01-2496, presented 33 ${ }^{\text {rd }}$ International Conference on Environmental Systems, 2003.

8 Murdoch, K.E., Scull, T.D., Carrasquillo, R.L., and Graf, J., Sabatier $\mathrm{CO}_{2}$ Reduction System Design Status, SAE Paper No. 2002-01-2531, presented $32^{\text {nd }}$ International Conference on Environmental Systems, 2002.

9 Jeng, F.F., and Lin, C.H., A Trade Study on Sabatier $\mathrm{CO}_{2}$ Reduction Subsystem for Advanced Missions, SAE Paper No. 200101-2293, presented $31^{\text {st }}$ International Conference on Environmental Systems, 2001.

${ }^{10}$ Murdoch, K.E., and Allen, G.F., Jr., Parametric Impacts on Sabatier Water Production Capability, SAE Paper No. 1999-012121, presented $29^{\text {th }}$ International Conference on Environmental Systems, 1999.

${ }^{11}$ Zubrin, R. Price, S., Mason, L., Report on the Construction and Operation of a Mars In-Situ Propellant Plant., AIAA-94-2844, presented 30th AIAA/ASME Joint Propulsion Conference, Indianapolis, IN, June 1994.

12 Zubrin, R. Price, S., Mason, L., Mars Sample Return With In-Situ Resource Utilization: An End-to-End Demonstration of a Full Scale Mars In-Situ Propellant Production Unit, Final Report NASA Contract NAS-9-19145, Jan. 1995.

${ }^{13}$ Nakata, A., Matsumoto, H., Hatano, S., Kita, Y., and Shimoda, T., Fundamental Study of Water Generation System on Mars, SAE 2001-01-2413, presented 31 ${ }^{\text {st }}$ International Conference on Enviromental Systems, July 2001.

14 TeGrotenhuis, W.E., King, D.L., and Brooks, K.P., Optimizing Microchannel Reactors by Trading-Off Equilibrium and Reaction Kinetics through Temperature Management, presented AIChE Spring National Meeting, March 2002.

15 Brenchley, D.L., Applications of Micro Chemical and Thermal Systems, presented AIChE Spring National Meeting, March 2001.

${ }^{16}$ Strumpf, J.J., et al., Sabatier Carbon Dioxide Reduction System for Long-Duration Manned Space Application, SAE Technical Paper Series No. 911541, Society of Automotive Engineers, Warrendale, PA, 1991.

${ }^{17}$ Lunde, P.J. Modeling, Simulation, and Operation of a Sabatier Reactor, Ind. Eng. Chem., Process Des. Dev., 13 (3), $226-232$, 1974.

${ }^{18}$ Atwater, J.E., Wheeler, R.R., Jr., Hadley, N.M., Dahl, R.W., and Carrasquillo, R.L., Development and Testing of a Prototype Microwave Plasma Reactor for Hydrogen Recovery from Sabatier Waste Methane, SAE Paper No. 2009-01-2467, presented at the $39^{\text {th }}$ International Conference on Environmental Systems, Atlanta, July 2009.

${ }^{19}$ Wheeler, R.R., Jr., Hadley, N.M., Dahl, R.W., and Atwater, J.E., Operations Manual: First Generation Prototype Microwave Plasma Reactor for Hydrogen Recovery from Waste Methane, NASA Contract: NNM07AA14C, March 2009.

20 Atwater, J.E., Wheeler, R.R., Jr., Hadley, N.M., Dahl, R.W., and Carrasquillo, R.L., Hydrogen Recovery by Methane Decomposition in a Microwave Plasma Reactor, SAE Paper No, 2008-01-2099, presented $38^{\text {th }}$ International Conference on Environmental Systems, San Francisco, June 29-July 2, 2008.

${ }^{21}$ Atwater, J.E., Akse, J.R., Wheeler, R.R., Jr., Dahl, R.W., Zavala, D.B., Jr., Hanken, B.E., Holtsnider, J.T., Williams, T.W., and Nanci, J.C., Hydrogen Recovery by ECR Plasma Pyrolysis of Methane, URC 81164, Final Report, NASA Contract NNM06AA45C, July 2006.

${ }^{22}$ Abney, M. B., Miller, L. A., and Barton, K., Evaluation of Sorbents for Acetylene Separation in Atmosphere Revitalization Loop Closure, AIAA Paper No. 2011-5057, presented at the $41^{\text {st }}$ International Conference on Environmental Systems, Portland, 2011.

${ }^{23}$ Mansell, J. M., Abney, M. B., and Miller, L. A., Influence of Oxygenated Compounds on Reaction Products in a Microwave Plasma Methane Pyrolysis Assembly for Post-Processing of Sabatier Methane, AIAA Paper No. 2011-5035, presented at the $41^{\text {st }}$ International Conference on Environmental Systems, Portland, 2011.

${ }^{24}$ Abney, M. B., Miller, L. A., and Williams, T., Sabatier Reactor System Integration with Microwave Plasma Methane Pyrolysis Post-Processor for Closed-Loop Hydrogen Recovery, AIAA Paper No. 2010-6274, presented at the $40^{\text {th }}$ International Conference on Environmental Systems, Barcelona, July 2010.

${ }^{25}$ Fridman, A., Plasma Chemistry, Cambridge University Press, New York, New York, 2008. 